\title{
Comparative study of geometrical configuration at the thermal performances of an agricultural greenhouse
}

\author{
Lalmi Djemoui ${ }^{1, *}$, Hocine Bensaha ${ }^{1}$, Abdelouahab Benseddik ${ }^{1}$, Ridha Zarrit $^{1}$, \\ Mawloud Guermoui ${ }^{1}$, Abdelaziz Rabehi ${ }^{1}$ and Mohamed Tahar Bouzaher ${ }^{1}$ \\ ${ }^{1}$ Unité de Recherche Appliquée en Energies Renouvelables, URAER, Centre de Développement des \\ Energies Renouvelables, CDER, 47133, Ghardaïa, Algeria
}

\begin{abstract}
The aims objective of this work consists to study the storage system effects on the thermal performance of a tunnel agricultural greenhouse. The study focus on the use of the data climate analysis to predict the outside needs as comparison with another without storage system. The obtained results indicate that the outside needs are less than the no heated with 3 to $5^{\circ} \mathrm{c}$ during winter night. The thermal behavior of the greenhouse was study numerically and the results are corroborating with the literature. In addition, we conducted a comparative study designed to identify the optimal form of the greenhouse; two geometrical configuration are considered.
\end{abstract}

\section{Introduction}

The greenhouse is a production tool used to create artificially a microclimate to promote growth and development of culture. By its presence, it protects vegetation from blows due to changes in climate factors [1]. The main greenhouse environmental factors, which are different from the outside, are temperature, light and humidity. Each of these factors is conditioned in the greenhouse, by its level outside the enclosure, by the properties of the roofing material and by the characteristics specific to this greenhouse [2-3].

Tunnel-type plastic greenhouses are widely used around the world, especially in the Saharan countries because of their low investment cost [4].

These are efficient in winter and spring, where solar energy is useful and sufficient for greenhouse production. On the other hand, these greenhouses lose their effectiveness in summer where, the climate is very hot, which causes excessive overheating and strong hygrometries inside [5].

These extreme weather conditions affect the quality and quantity of the product and promote the development of certain diseases. On the physical plane, the greenhouse is a complex energy system in which all the different modes of thermal and mass exchange. If

* Corresponding author: eldjemoui@gmail.com 
they are relatively simple and well known, their coupling causes difficulties in the modeling of the system [6-7].

In this system, natural convection is a particularly important mechanism for heat exchange between indoor air and all other solid surfaces (floor, walls, roof, culture, air conditioning and heating systems)[8].The aim objective of this study consists predict the storage system effect at the thermal behavior of an agricultural greenhouse in semi-arid climate. The study base on the use of the date climate to ameliorate the efficient of the production in this region with excess temperature. The outline of paper is: We start by an introduction; the potential solar is treated in the second parts. The third parts reserved to the description of the experiment. In fourth parts, we interpreted the results and discus and we finish by a conclusion and some perspectives.

\section{Description of the experimental potential solar energy area study}

In this study, experiments were carried out in two greenhouse at the Applied Research Unit on Renewable Energy at Ghardaïa from Algeria.Around of $77 \%$ of Algerian area presented arid and semi-arid regions. The characteristics of this region (Ghardaïa) are:

- Location $595 \mathrm{Km}$ south of the Mediterranean sea

- Latitude and $32^{\circ} 36 \mathrm{~N}$

- Longitude $3^{\circ} 80 \mathrm{E}$

- Altitude of $469 \mathrm{~m}$ above the sea level

- Rate of sunny days per year: $77 \%$

- Annual daily average of global solar irradiance about $7 \mathrm{kWh} / \mathrm{m}^{2}$ at horizontal surfaces.

Fig. 1 show the variation of the average monthly global solar radiation in a period of 2016 [2-3].It can see that the global solar flux has the same trend of variation as the ambient temperature Fig.2 [1]. It is observed that the peak of average monthly radiation is registered in May, June, July and august $\left(6000 \mathrm{~W} / \mathrm{m}^{2}\right)$ with a highest monthly ambient temperature surrounding $38^{\circ} \mathrm{C}$. The least average monthly radiation is $2900 \mathrm{~W} / \mathrm{m}^{2}$ with a monthly ambient temperature around $10^{\circ} \mathrm{C}$ in January and December. Figs.3and 4 gives the variation of the instannious monthly ambient temperature and relative humidity in four season of period of 2016. We can see that the ambient temperature passed the $40^{\circ} \mathrm{C}$ in august where the relative humidity passed $85 \%$ in January. An experimental study has carried out during the month of January 2016, which is the winter season.

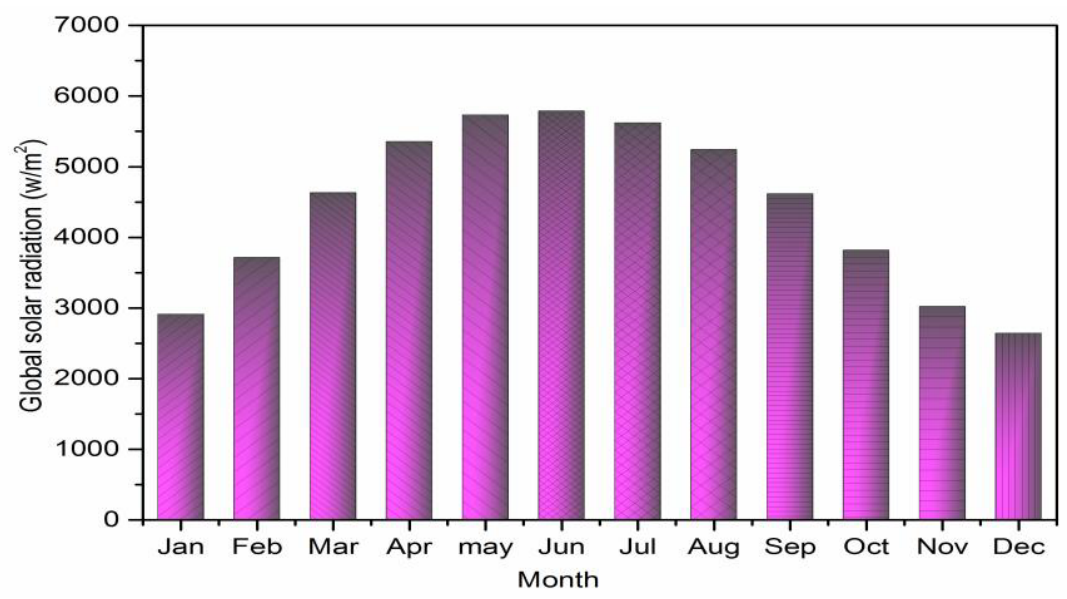


Fig. 1. Monthly variation of the global solar radiation for the year 2016 in Algeria.

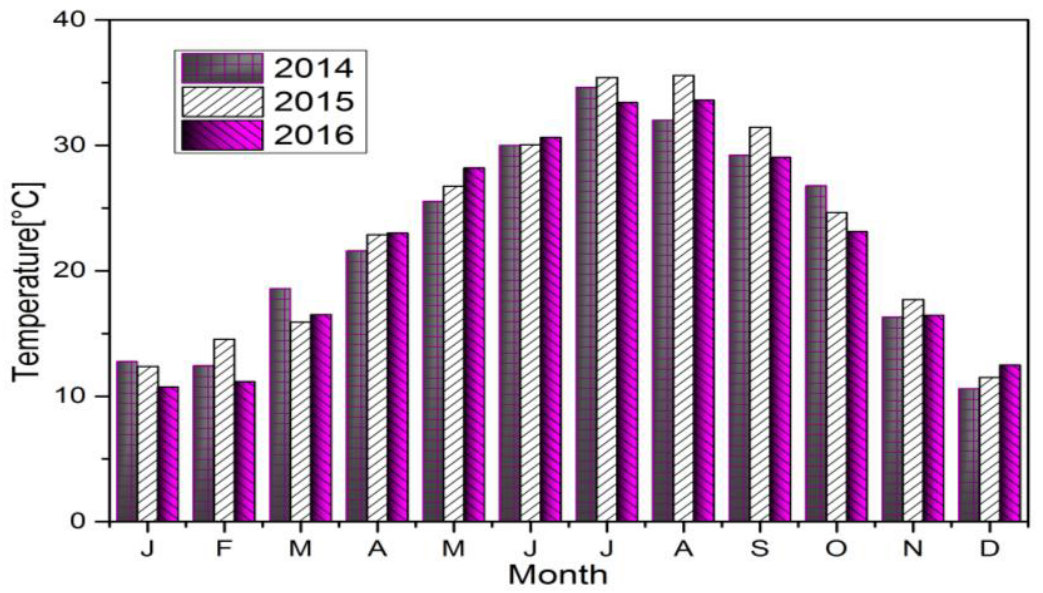

Fig. 2. Monthly variation of the mean ambient temperature in three years at Ghardaïa.

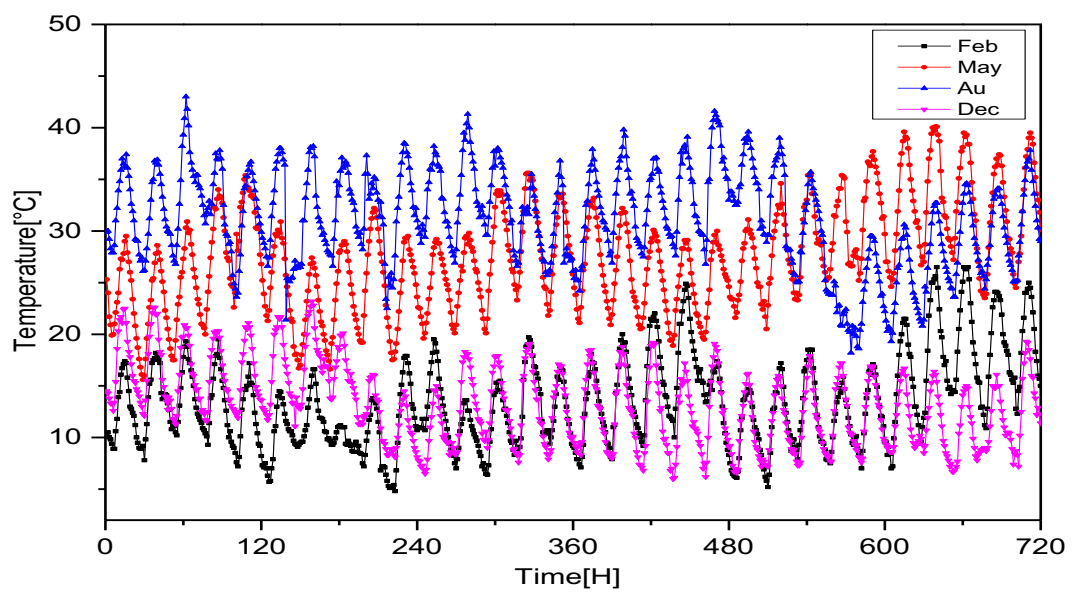

Fig. 3. Instannious temperature evolution in four month Feb, May, Aug and December2016.




Fig. 4. Instannious relative humidity evolution in four month Feb, May, Aug and December 2016.

\subsection{Experimental investigation}

The two tunnel greenhouse test bench complete occupied and without storage system are shown in the Fig.5. It has a height of $3 \mathrm{~m}, 25 \mathrm{~m}$ of length and $8 \mathrm{~m}$ of width, which leads to a volumetric of $528 \mathrm{~m}^{3}$. The greenhouse has a north-south direction, with optimal deviation angle of $32^{\circ}$ to the West. It has doors (opening) at the side walls create for ventilation [11-12]. The polyethylene covers the experimental greenhouse with a low density, extensible and a $0.18 \mathrm{~mm}$ thickness. Polyethylene had a low and diffusion temperature respectively about $-110^{\circ} \mathrm{C}$ and $140^{\circ} \mathrm{C}$.

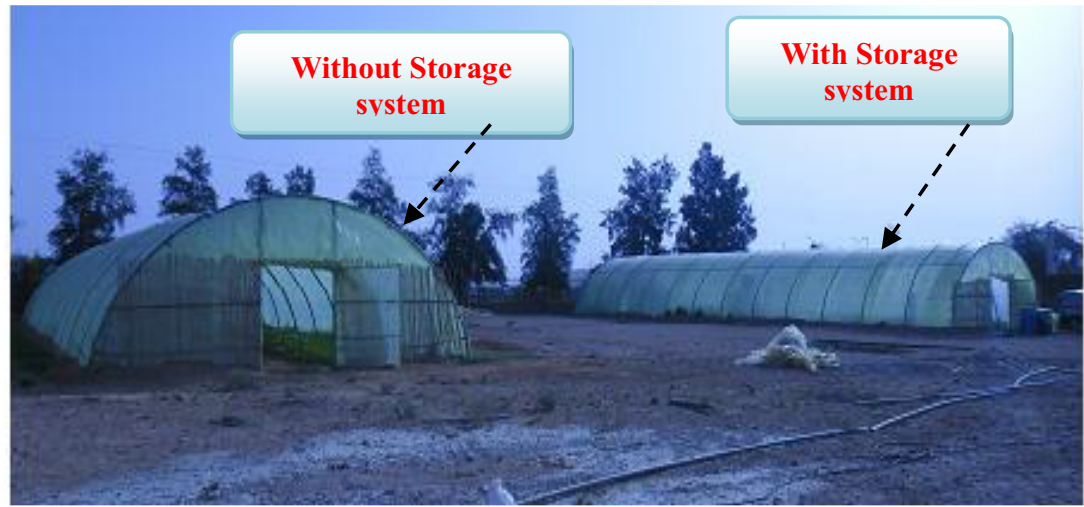

Fig. 5. The two greenhouses test facility in URAER

\subsection{Description of the storage system}

Design steps of thermal storage system are presented in the Fig.6 and 7.It consists of the following parts:

- Four (4) PVC cylindrical pipes of $200 \mathrm{~mm}$ of diameter, implemented on the $\mathrm{H}$ position form.

- $\quad$ These pipe fields by stones

- Stones having 50 to $100 \mathrm{~mm}$ of approximate diameter.

- The storage system implemented about $0,70 \mathrm{~m}$ away from the depth.

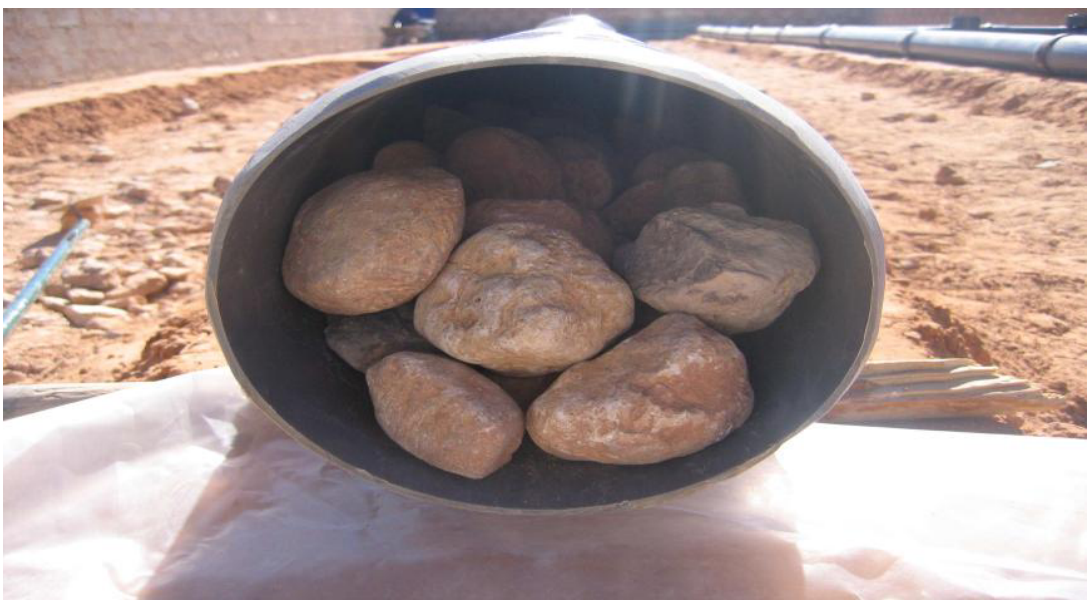


Fig. 6. PVC pipe rumpled with stones

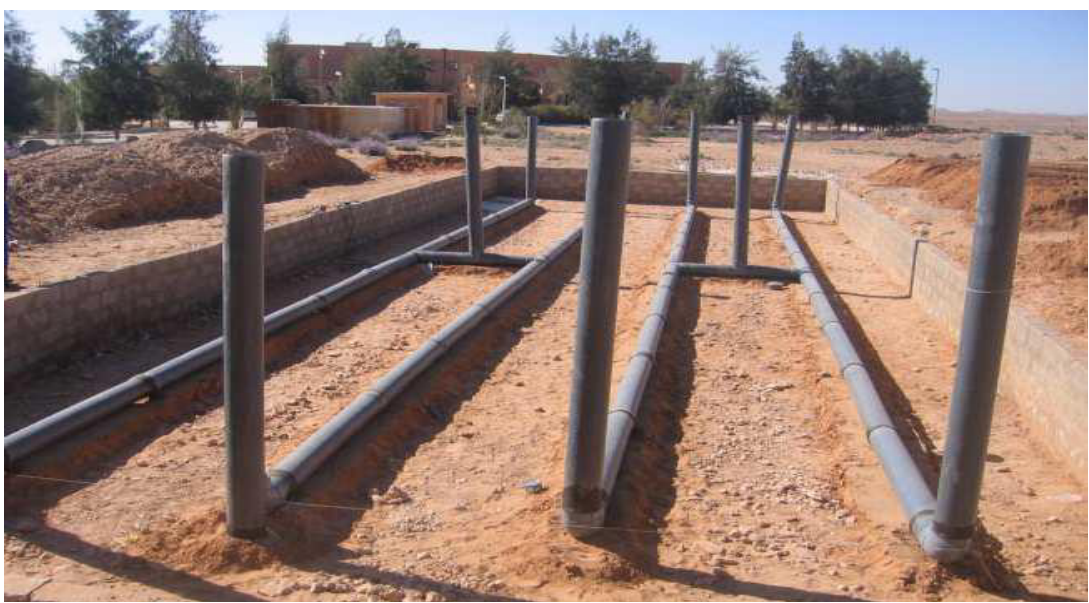

Fig. 7. PVC Emplacement

\section{Experimentation and results}

In the two greenhouses with and without storage system, courgettes plants are transplanted on the 27 th of December 2017 and the harvesting started on the 14 th of March 2018. The major environmental factors that affect the growth and the precocity of the production of greenhouse plants are temperature, light and humidity. The courgettes plants have two optimum temperatures, one during the day; which varied between 24 and $32{ }^{\circ} \mathrm{C}$, and the other nocturnal temperature that is the most crucial temperature varied between 16 and $19{ }^{\circ} \mathrm{C}$. A courgettes crop (local variety) was planted in both greenhouses, planted at 20 plants in the row, and arranged in (8) eight rows with $30 \mathrm{~cm}$ between the rows and $20 \mathrm{~cm}$ between the plants. During the growing period, the January has the least average monthly radiation is $2600 \mathrm{~W} / \mathrm{m}^{2}$ with a monthly ambient temperature around $10^{\circ} \mathrm{C}$ (Fig.2 and 3).

The heating requirements of both greenhouses with and without storage system at night, are shown in Fig. 8 with a set temperature point of $17^{\circ} \mathrm{C}$ (required temperature for plants at night our case courgettes).

The curves show that the needs of the experimental greenhouse occupied with the storage system are lower than the without storage system with difference between 3 to $5^{\circ} \mathrm{C}$ per night. 


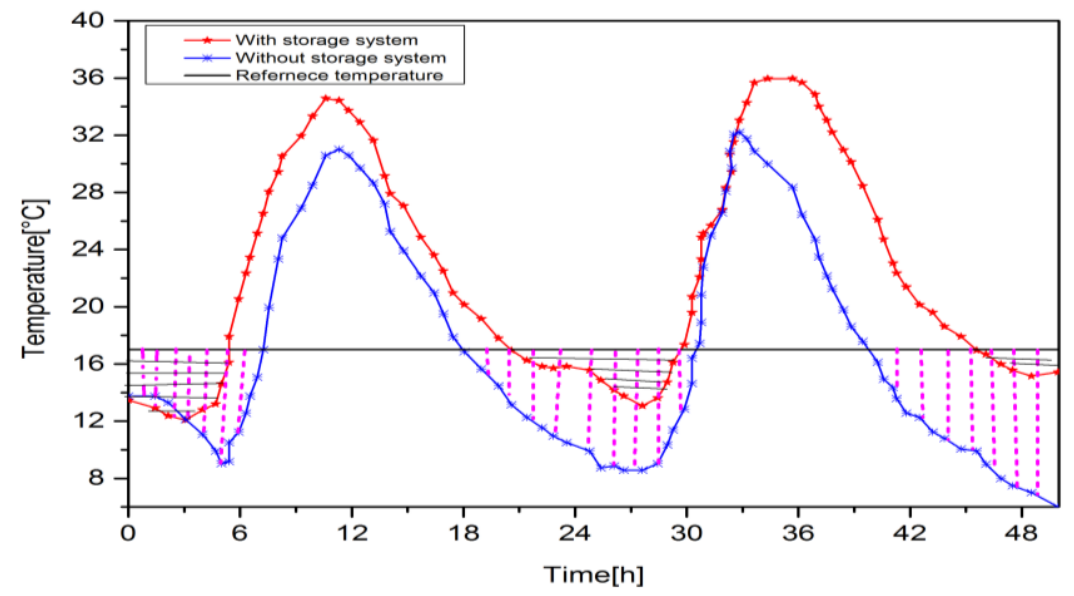

Fig. 8. Temperature evolution at night of both greenhouses (heating requirement).

\section{Numerical study}

The aim objective of this investigation is to study the air behavior evolution inside the heated greenhouse without vegetal cover by comparison with an author chapel greenhouse. The Ansys software 16.0 code used. Flow considered laminar in two-dimensional along $x$ and $y$, where the Physical properties of air supposed constant, except its density $(\rho)$ whose variation was given by the Boussinesq approximation [13-14-15-16]:

$$
\rho=\rho_{0}\left(1-\beta\left(T-T_{0}\right)\right)
$$

\subsection{Geometrical configuration}

Geometrical configuration with all boundaries condition considered in this study showed in the Fig.9.
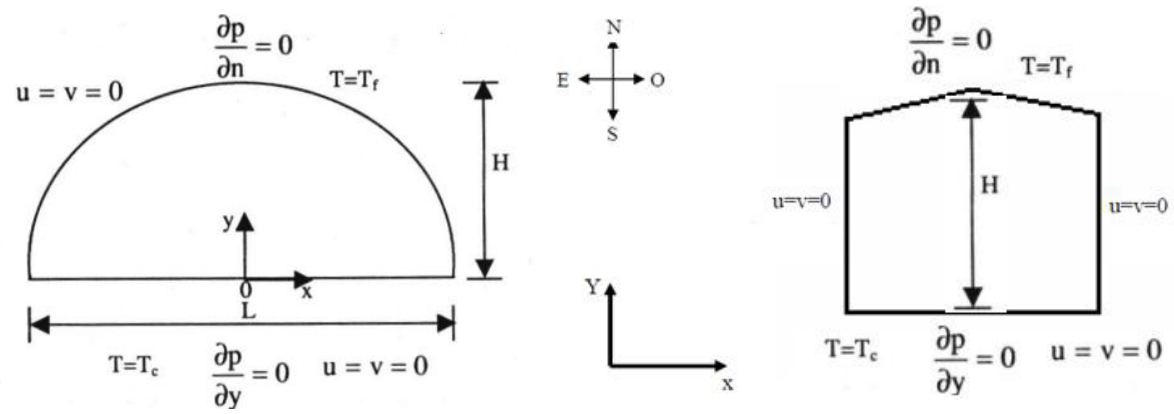

Fig. 9. Problem Position and boundary condition for tunnel greenhouse

\subsection{Simulation results}

Streamlines and isotherms for different Rayleigh numbers (Ra) are shown in Fig.10 and 11. Fluid flow intensifies and natural convection increases and predominates on conduction. 
The heated air particles at ground level rise along the wall then, cooled particles in contact with roof goes approximately to the author walls. The influence of Rayleigh number on the streamline (top the fig.10 and bottom the fig.11) and the isotherms (bottom of the Fig.10and top of the Fig.11) is illustrated. With different Rayleigh numbers the flow characterized by two air circulation loops in both cases. For small Rayleigh numbers (between $\mathrm{Ra}=104$ to 105), the isotherms are parallel. This representation indicate that the heat transfer dominated by conduction.

When the Rayleigh number increases, isotherms becomes more and more wavy and transfer heat exchange was more pronounced in the two cases, tunnel and chappel greenhouse. As this obtained result, fluid flow intensifies and natural convection increases and dominates conduction. The heated air particles at ground level rise along the wall. Then, the cooled particles in contact with the roof flow approximately a median plane.

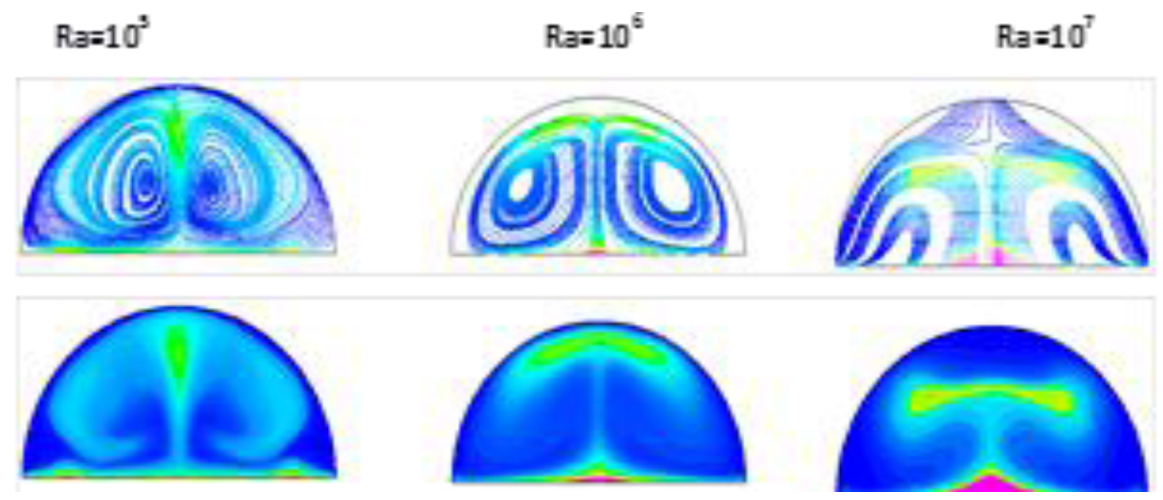

Fig. 10. Isolignes and isothermal evolution in tunnel greenhouse

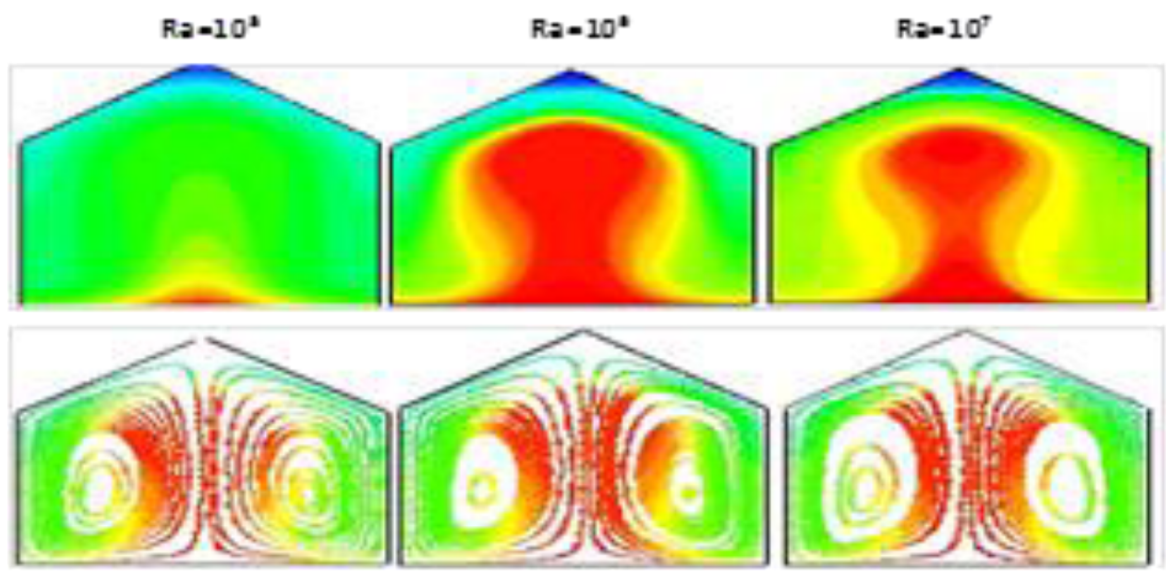

Fig. 11. Isolignes and isothermal evolution in Chappel greenhouse

\section{Rayleigh number Effect's at the heat transfer exchange}

The exchange heat transfer evolution in the both proposed geometrical configuration of greenhouse for different Rayleigh numbers represented by the local Nusselt number in Fig.12 and (13).Therefore, the logic was respected as long as there is a concentration of isotherms at the corners (ground), which explains a large number of Nusselt. It was found 
that for a small Rayleigh number varying between $10^{4}$ to $10^{5}$, the Nusselt number of is small and it is the conduction that dominates. With increase of Rayleigh number, the exchange rate increases and the local Nusselt number becomes important in the tunnel compared with the chappel greenhouse. The rate transfer represented according to the mean Nusselt number Fig.14. It can be see that the tunnel is higher losses compared to the chappel. Finally, from these results; we can observe the good according between the literature and the present work for different Rayleigh numbers.

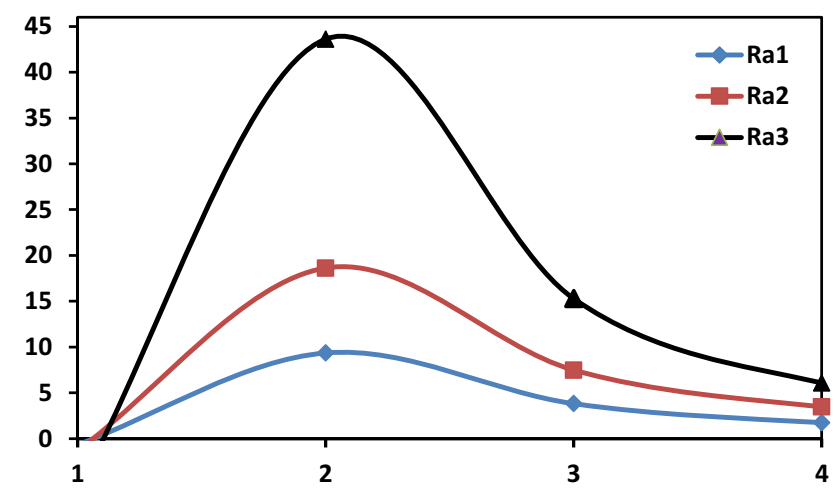

Fig. 12. Local Nusselt Number evolution in tunnel greenhouse at three values of Rayleigh number $\mathrm{Ra}=10^{5}, 10^{6}$ and $10^{7}$

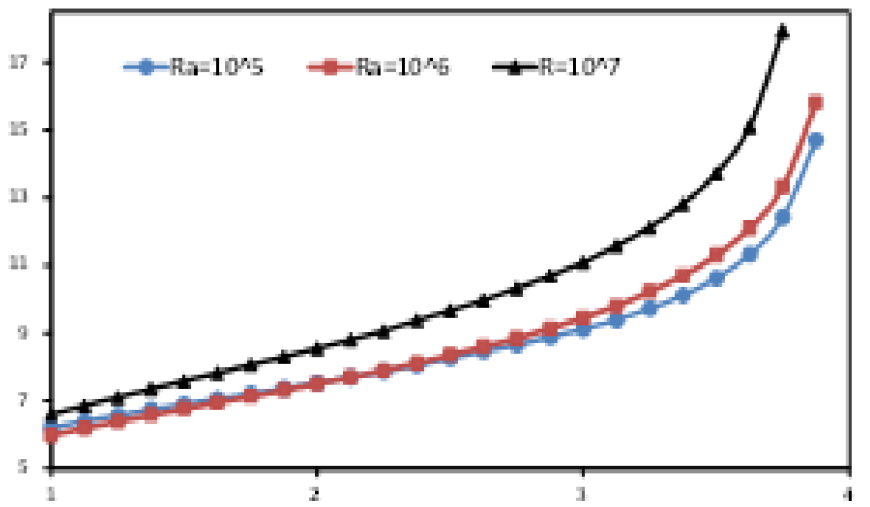

Fig.13. local Nusselt Number evolution in Chapel greenhouse at three values of Rayleigh number $\mathrm{Ra}=10^{5}, 10^{6}$ and $10^{7}$ 


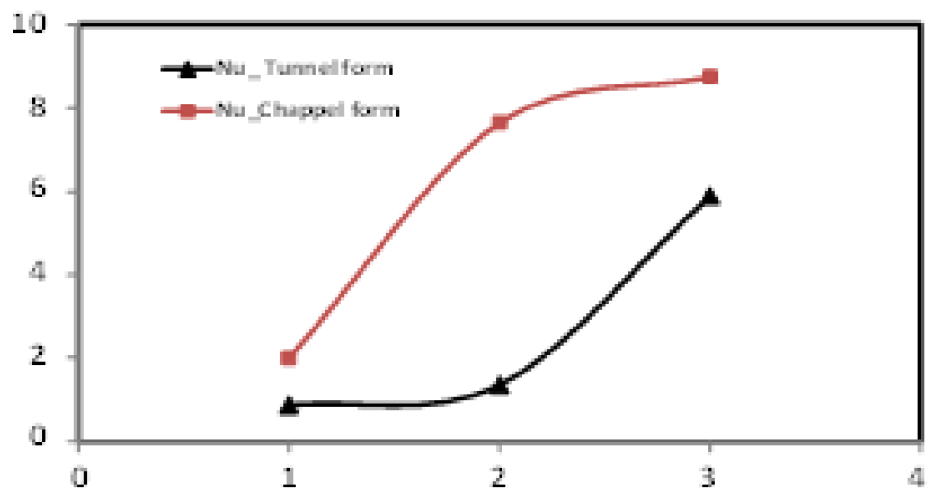

Fig.14. Mean Nusselt number evolution in tunnel and Chappell greenhouse

\section{Conclusion}

Our objective was to study the storage system effects and the air behavior inside the greenhouse.The thermal performences of the heated grenhouse are ameliorated with outsit needs between 3 to $5{ }^{\circ} \mathrm{C}$.Numerical similation was conducted to predict the air behvior inside the grenhouse by the spatiotemporal distributions of isolignes and isothermal.We have also shown that for the conditions imposed on the and for low differences temperature between floor and roof, the air circulation is characterized by two recirculation cells rotating in the opposite direction. Therefore, this study should make it possible to improve the thermal design of greenhouse as well as the positioning of heating systems with thermal storageand geometrical configuration.

\section{References}

1. D. Lalmi, S. Bezari, H. Bensaha, M. Guermoui, A. Rabehi, B. Abdelouahab, R. Hadef, Analysis of thermal performance of an agricultural greenhouse heated by a storage system, Modelling, Measurement and Control B, (2018)

2. Abdelaziz Rabehi, Mawloud Guermoui, Lalmi Djemoui, Hybrid Models for Global Solar Radiation Prediction: case of study, International Journal of Ambient Energy, (2018).

3. Reski Khelifi ,Guermoui Mawloud, Rabehi Abdelaziz, Lalmi Djemoui , Multi-Step Ahead Forecasting of Daily Solar Radiation Components in Saharan Climate, International Journal of Ambient Energy, (2018)

4. Naijun Zhou , Yaxiong Yu , Jinping Yi, Rui Liu ,A study on thermal calculation method for a plastic greenhouse with solar energy storage and heating ,Solar Energy 142 (2017) 39-48

5. Nessim Arfaoui, Salwa Bouadila, Amenallah Guizani ,A highly efficient solution of off-sunshine solar air heating using two packed beds of latent storage energy, Solar Energy 155 (2017) 1243-1253

6. M. Lazaar, S. Kool P, M. Hazam P, A. Farhat a, A. Belghith, Use of solar energy for the agricultural greenhouses Use of solar energy for the agricultural greenhouses autonomous Conditioning, Desalination 168 (2004) 169-175 
7. T. Boulard, S. Wang, Greenhouse crop transpiration simulation from external climate conditions, Agricultural and Forest Meteorology 100 (2000) 25-34

8. A.Bouhdjar, M. Belhamel, F.E. Belkhiri and A. Boulbina, Performance of sensible heat storage in a rock bed used in a tunnel greenhouse. WREC 1996

9. F. Berroug, E.K. Lakhal, M. El Omari, M. Faraji and H. El Qarnia, Numerical Study of Greenhouse Nocturnal Heat Losses, Journal of Thermal Science Vol.20, No.4 (2011) 377

10. Dewanto Harjunowibowo, Erdem Cuce, Siddig A. Omer, Saffa B. Riffat, Recent Passive Technologies of Greenhouse Systems-A Review, 15th International Conference on Sustainable Energy Technologies - SET 2016, 19 th -22nd of July 2016, National University of Singapore, Singapore

11. Erdem Cuce, Dewanto Harjunowibowo, Pinar Mert Cuce ,Renewable and sustainable energy saving strategies for greenhouse systems: A comprehensive review, Renewable and Sustainable Energy Reviews 64 (2016)34-59.

12. George C. Bakos, Dimitrios Fidanidis, Nikolaos F. Tsagas, Greenhouse heating using geothermal energy, Geothermics 28 (1999) 759-765

13. Bezari S, Lalmi D, Babbou A. (2016).Heating of greenhouse with storage system: study and investigation. 4th international conference on Renewable Energies (CIER_2016) Proceedings of Engineering and Technology 14: 23-28.

14. Babbou A, Ziari YK, Lalmi D, Bezari S, Zarit R, Bensaha H.. Effect of operational parameters on the performance of heat storage in a rock bed used in a tunnel greenhouse. The 4th International Seminar on New and Renewable Energies, Ghardaiia - Algeria (2016).

15. Lalmi D, Hadef R, Babbou A, Bensaha H, Bezari S, Zarit R. Numerical study of air behavior in a greenhouse Equipped with a thermal storage system. The 4th International Seminar on New and Renewable Energies, Ghardaïa - Algeria (2016).

16. D.Lalmi \& R.Hadef, Numerical simulation of co and counter swirls on the isothermal flow and mixture field in a combustion chamber, Advances and Applications in Fluid Mechanics, AAFM, Vol. 18, issue 2:199-212 


\section{Nomenclature}

$\mathrm{Ra}$ Rayleigh number

$\mathrm{Ra} \quad$ Reynolds number

Nux Local Nusselt Number

Num Mean Nusselt Number

$\mathrm{Pr} \quad$ Prandtl number

Re Reynolds number

Pve Plastic pipe

$I_{t} \quad$ total solar radiation $(W=m 2)$

A surface area $\left(\mathrm{m}^{2}\right)$

$m \quad \operatorname{mass}(\mathrm{kg})$

$Q$ heat rate $(W)$

$t \quad$ time (s)

hi Convective heat transfer

coefficient between liquid and

$P \quad$ Pressure (pas)

$C p \quad$ specific heat of air at constant pressure $(\mathrm{J} / \mathrm{kgK})$

$T \quad$ Temperature

$U \quad$ velocity $(m=s)$

$V \quad$ volume $\left(\mathrm{m}^{3}\right)$

$Y \quad$ depth of soil $(\mathrm{m})$

$M \quad$ mass flow rate $\left(\mathrm{kg} / \mathrm{s}^{-1}\right)$

$\mathrm{D}_{0} \quad$ Diameter $(m)$

D diffusion coefficient

\section{Exposants}

Cd conductive heat

$C v$ convective heat

$L$ latent heat

$R$ radiation heat

\section{Subscript}

Max maximum

Min minimum

$H$ heat gain

A absorbed

a ambient

co cover of greenhouse

$b$ bottom

e edge

to top

pol polyethylene

av average

inl inlet greenhouse

in inside greenhouse

out outside greenhouse

so soil

sts $\quad$ storeg system

\section{Greek Symbols}

$\varepsilon \quad$ emissivity

$\Delta \quad$ difference in time

$\lambda$ Thermal conductivity $(\mathrm{W} / \mathrm{mK})$

$\alpha \quad$ thermal diffusivity

$\mu \quad$ dynamic viscosity $\left(\mathrm{Ns} / \mathrm{m}^{2}\right)$ 